\title{
Water Resources Adaptation to Climate and Demand Change in the Potomac River
}

\author{
James H. Stagge, Ph.D., P.E. ${ }^{1}$; and Glenn E. Moglen, Ph.D., P.E., F.ASCE ${ }^{2}$
}

\begin{abstract}
The effects of climate change are increasingly considered in conjunction with changes in water demand and reservoir sedimentation in forecasts of water supply vulnerability. Here, the relative effects of these factors are evaluated for the Washington, DC metropolitan area water supply for the near (2010-2039), intermediate (2040-2069), and distant (2070-2099) future by repeated water resources model simulations. This system poses water management challenges because of long water-delivery travel times that increase uncertainty, multiple water jurisdictions that constrain potential decisions, and future scenarios that simultaneously increase demand and decrease water supply during the critical summer period. Adaptation strategies were developed for the system using a multiobjective evolutionary algorithm. Optimized reservoir management policies were compared using six distinct objectives ranging from reservoir storage to environmental and recreational benefits. Simulations of future conditions show water stress increasing with time. Reservoir sedimentation is projected to more than double (114\% increase) the severity of reservoir storage failures by 2040 . Increases in water demand and climate change are projected to further stress the system, causing longer periods of low flow and a loss of recreational reservoir storage. The adoption of optimized rules mitigates some of these effects, most notably returning simulations of 2070-2099 climate to near historical levels. Modifying the balance between upstream and downstream reservoirs improved storage penalties by $20.7 \%$ and flowby penalties by $50 \%$. Changing triggers for shifting load to off-line reservoirs improved flowby (8.3\%) and environmental (4.1\%) penalties slightly, whereas changing demand restriction triggers provided only moderate improvements, but with few adverse effects. DOI: 10.1061/(ASCE) HE.1943-5584.0001579. () 2017 American Society of Civil Engineers.
\end{abstract}

Author keywords: Water resources management; Optimization; Climate change adaptation; Drought.

\section{Introduction}

Climate research indicates that the Earth's climate is changing in response to changes in the global atmospheric composition, brought about by human activities (IPCC 2014). With atmospheric research improving the reliability of climate projections, water resources planners and engineers must consider climatic changes as important factors for water supply planning, along with more traditional nonstationary factors such as demand change and reservoir sedimentation. Once future vulnerabilities to any of these factors are identified, adaptation strategies can be developed to mitigate their effects. Like many major cities, the Washington, DC metropolitan area (WMA) is interested in identifying changes in water supply vulnerability arising from (1) increased water demand, (2) losses of storage, and (3) changes in natural water availability because of the effects of climate change. This study explores these questions and demonstrates how water resources optimization can be combined with projections of future conditions to develop adaptation strategies using the WMA as a case study.

${ }^{1}$ Postdoctoral Fellow, Dept. of Civil and Environmental Engineer ing, Utah State Univ., Logan, UT 84321; formerly, Virginia Tech Univ., Blacksburg, VA 24061 (corresponding author). E-mail: james.stagge@ usu.edu

${ }^{2}$ Supervisory Research Hydrologist, U.S. Dept. of Agriculture, Hydrology and Remote Sensing Lab, Agricultural Research Service, Beltsville, MD 20705.

Note. This manuscript was submitted on February 8, 2017; approved on May 10, 2017; published online on September 13, 2017. Discussion period open until February 13, 2018; separate discussions must be submitted for individual papers. This paper is part of the Journal of Hydrologic Engineering, (C) ASCE, ISSN 1084-0699.
The WMA is the sixth largest metropolitan area in the United States (U.S. Census Bureau 2016), housing an estimated 6.1 million residents across 15 counties in Maryland (MD), Virginia (VA), and the District of Columbia (DC). Each of these three regions operate under separate water suppliers, creating an interesting jurisdictional challenge that was largely addressed by a unique shared decisionmaking scheme designed to ensure equitable water access during water shortages (U.S. Army Corps of Engineers 1982). Water for the region (Fig. 1) is primarily provided by withdrawals from the Potomac River, whose flow can be augmented by the Jennings Randolph Reservoir, located a 9-10 day travel time (300 km) upstream of the Washington, DC water supply intakes, and the smaller Little Seneca Reservoir, located only a 1-day travel time upstream, which can be used to fine-tune releases (Sheer and Flynn 1983). This design, completed in 1982, allows the $38,000 \mathrm{~km}^{2}$ Potomac watershed to remain largely uncontrolled, but also increases the importance of effective water management policies. Maryland and Virginia maintain off-line water storage, the Patuxent and Occoquan Reservoirs, respectively, which can supplement water extracted from the Potomac River. In 2008, 31\% of suburban Maryland's water production came from the Patuxent Reservoir and $42 \%$ of suburban Virginia's water production came from the Occoquan Reservoir, with the remainder and all of Washington DC's water supply coming from the Potomac River. More details and history of the WMA water supply system have been offered by Stagge and Moglen (2014) and Sheer and Flynn (1983).

Optimization of the WMA water supply system has its origins in the initial water-allocation studies (Palmer et al. 1979, 1982), which concluded that demand could be met through coordinated operation of the existing Patuxent and Occoquan Reservoirs, along with the Jennings Randolph and a then-proposed reservoir, which would eventually become the Little Seneca Reservoir. The system has been 


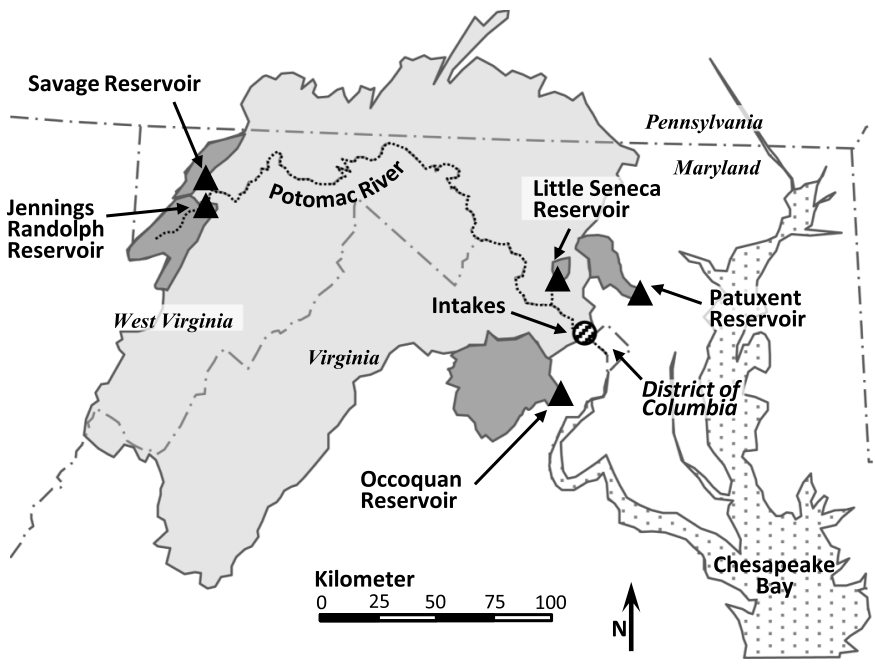

Fig. 1. Potomac watershed and Washington, DC, water supply; Potomac watershed shown in lighter shade, with reservoir watershed shown in a darker shade; reservoirs shown as triangles and intakes for the Washington, DC, metropolitan area shown as a hashed circle

stressed several times, with water supply releases made on three occasions, in 1999, 2002, and 2010. Following the 1999 drought event, specific triggers were added to the management plan that guaranteed all regions (MD, VA, and DC) would enact water-use restrictions automatically and simultaneously to prevent jurisdictional disagreements. In an optimization study of the region, Stagge and Moglen (2014) concluded that these triggers were unnecessarily conservative, never engaging during simulations of the historical drought of record, and that accepting infrequent use restrictions would greatly decrease the system's vulnerability. Stagge and Moglen (2014) considered other water management rules, concluding that improvements to reservoir storage and environmental flowby could be achieved by modifying rules that shift demand from the Potomac River to the off-line reservoirs. Rules controlling the relative releases from the Jennings Randolph and Little Seneca Reservoirs were found to be relatively well optimized, although a slightly stronger reliance on releases from the Little Seneca improved overall storage and downstream flow targets.

Projections of climate change effects in the Potomac River watershed and mid-Atlantic United States predict moderate increases in mean annual temperature, precipitation, and streamflow over the next century (Najjar et al. 2009; Pyke et al. 2008; Hayhoe et al. 2008). An evaluation of the four best-performing general circulation models (GCMs) in the Chesapeake Bay watershed suggested an increase in mean annual temperature of $3.9 \pm 1.1^{\circ} \mathrm{C}$ and an increase in precipitation of $9 \pm 12 \%$ by the end of the century under the A2 Scenario (Najjar et al. 2009). This continues the historical trend of precipitation increases throughout the northeast United States during the twentieth century (Groisman et al. 2001, 2004). Despite projected increases in mean annual precipitation and flow for the mid-Atlantic, variation in the seasonality and distribution of precipitation and runoff is potentially more important for water resources management. Storm events are projected to become both more severe and intermittent, with precipitation intensity expected to increase by one standard deviation, concurrent with an increase in dry days and heatwaves (Meehl and Tebaldi 2004; Tebaldi et al. 2006).

These projections suggest a moderate increase in mean flows, but with greater likelihood of flooding resulting from storm intensity, and drought attributable to prolonged dry periods. Seasonality is also expected to shift, with the greatest increase in precipitation occurring during the winter and spring (Najjar et al. 2009). Similar seasonal trends were found by Mccabe and Ayers (1989), Moore et al. (1997), and Hayhoe et al. (2007). This was further supported by detailed simulations of flow in the Potomac River that projected a slight increase (1-7\%) in mean annual flow by 2070-2099, with the increase occurring during the winter and early-spring peak season (Stagge and Moglen 2013). At the same time, summer flows are projected to decrease, caused by a decrease in runoff from large, sustained storm events, and the date of the minimum flow is expected to shift earlier by 2-5 days (Stagge and Moglen 2013).

In addition to climate change, demand increases and loss of storage due to sedimentation will further stress the system. The population of the WMA was predicted to increase by approximately 1 million people (25\%) between 2010 and 2040, which corresponds to a projected water demand increase of 23\% (MWCOG 2009). According to the most recent Census estimates (U.S. Census Bureau 2016), the region's population has already increased by 460,000 during the first 5 years of this period (2010-2015). Adding to this potential system stress, reservoirs in the WMA water supply system are projected to lose $7-15 \%$ of their usable storage volume due to sedimentation in the 30 years between 2010 and 2040 (Ahmed et al. 2010)

This study has two primary objectives: (1) estimate future water supply vulnerability in the Potomac River and WMA, and (2) optimize water system rules based on future conditions and thereby provide adaptation strategies. The WMA represents an interesting challenge for this approach, given its tranboundary jurisdictional constraints and uncertainty because of the lag between reservoir releases and water delivery. Future conditions are simulated using the best available projections of demand change and reservoir sedimentation, whereas climate change effects are based on stochastically generated flows (Stagge and Moglen 2013) driven by Coupled Model Intercomparison Project Phase 3 (CMIP3) projections (Meehl et al. 2007). Adaptation strategies are derived by considering several conflicting objectives using start-of-the-art multiobjective evolutionary algorithm optimization. The advantage of this approach is a greater flexibility in objectives and system models that still allows decision makers to easily compare alternatives by metrics that are used in practice. The resulting strategies show how current levels of service in the WMA could be maintained in the future using only better management, avoiding the need for physical modification to the system. This demonstrates an approach merging climate projections and optimization that could be replicated in other water systems to develop adaptation strategies.

\section{Methods}

This study extends prior research on optimal water management on the Potomac River under current conditions Stagge and Moglen (2014) to instead test the vulnerability of the WMA water supply system to projected future climate, demand, and storage changes and then address the critical topic of adaptation to these future conditions. Future vulnerability was tested by comparing system performance using current conditions to three future climate periods (2010-2039, 2040-2069, and 2070-2099) and projections of demand and reservoir sedimentation at 5-year intervals from 2010 to 2040. Vulnerability was estimated for each of these scenarios separately and together, and performance was quantified using six objective functions considered in previous studies of the system. Adaptation strategies were determined by optimizing system rules using a multiobjective evolutionary algorithm approach and highlighting how optimal rules might mitigate vulnerabilities identified in the first part of the study. 


\section{Washington Metropolitan Area Water Supply Model}

This study uses the water supply model developed and described in detail by Stagge and Moglen (2014). Hydraulic routing and reservoir operations were simulated using $O A S I S$, which is a water management simulation and decision model that uses a node-arc architecture to model reservoirs, reaches, inputs, and withdrawals. Operating rules are expressed as goals or constraints and solved via linear programming using a daily time step, mimicking the imperfect foresight of daily operational decision making.

The OASIS model was developed in conjunction with the Interstate Commission on the Potomac River Basin (ICPRB) and water suppliers to ensure that all data, operating rules, and assumptions were accurate. Reservoir details, including stage-storage curves, sedimentation rates, and existing operational rule curves, were provided by the ICPRB, along with the current Potomac channelrouting and travel-time estimates. Daily demand among the three major WMA water suppliers was simulated using a set of multivariate regression equations, incorporating an autoregressive movingaverage (ARMA) error term, provided by Ahmed et al. (2010). Municipal water needs of the WMA are managed by three major suppliers:

- Washington Suburban Sanitary Commission (WSSC), which serves the Maryland suburbs;

- Fairfax Water, which serves Fairfax County and other northern Virginia suburbs; and

- Washington Aqueduct, which provides water to the District of Columbia.

The current water supply system (Fig. 1) is the result of several design iterations and collaboration among the numerous levels of government, water suppliers, and citizen groups. The ICPRB's section for Cooperative Water Supply Operations on the Potomac (CO-OP), is responsible for coordinating water resources across these suppliers and stakeholders during times of low flow. Details of the system have been provided by Stagge and Moglen (2014) and Ahmed et al. (2010). This system relies predominantly (approximately 78\% annually, Ahmed et al. 2010) on flow from the Potomac River to satisfy water demands, with the remainder of water provided by two off-line reservoirs: the Patuxent Reservoir system operated by WSSC and the Occoquan Reservoir operated by Fairfax Water (Table 1). Flow along the Potomac is augmented by two reservoirs. The Jennings Randolph Reservoir is the larger of the two $\left(109 \times 10^{6} \mathrm{~m}^{3}\right)$, but is located approximately 9-10 days hydrologic travel time upstream of the WMA intakes (Table 1).
The Little Seneca Reservoir is located only 1 day upstream of the MWA intakes, but has significantly smaller usable storage and a smaller watershed area. These two reservoirs are, therefore, operated in concert, with the Jennings Randolph providing primary releases and the Little Seneca used to fine-tune flows immediately upstream of the intakes. The Savage Reservoir, located 8 km downstream from the Jennings Randolph Reservoir, is operated by the U.S. Army Corps of Engineers (USACE) in conjunction with the Upper Potomac River Commission (UPRC) to satisfy local North Branch low-flow requirements and supply water to the nearby town of Westernport, Maryland. It was not considered for optimization because it operates independently; however, the Savage Reservoir does make water supply releases during severe droughts according to a matching relationship with Jennings Randolph releases and therefore is also included in the model. This system layout possesses considerable uncertainty because release decisions must be made in advance of accurate weather forecasts yet still allow the main stem of the Potomac River to remain relatively uncontrolled.

\section{Climate Change Flow Simulation}

The effect of climate change was simulated by stochastically generating daily climate-adjusted streamflow and precipitation time series using the method described by Stagge and Moglen (2013). Five GCM models (Table 2) from the CMIP3 experiment (Meehl et al. 2007) were used to generate flows for three special report emissions scenarios (SRES A2, A1b, and B1). Projections of GCM-scale climate variables were related to discrete monthly climate states identified from the historical record for the study region. The Markov-chain transition probabilities between these climate states were then adjusted based on GCM climate projections. The parameters of a daily streamflow model, similar to those developed by Aksoy (2003) and Szilagyi et al. (2006), were defined by the monthly climate state and ultimately used to generate climate-adjusted daily streamflow. Daily flow was modeled using a two-state (increasing/decreasing) Markov chain, with rising limb increments randomly sampled from a Weibull distribution and the falling limb modeled as an exponential recession. This model was demonstrated to accurately reproduce historical streamflow statistics at the daily, monthly, and annual time steps in the Potomac River (Stagge and Moglen 2013) and to produce climate-adjusted streamflows that match the general findings of classical climate downscaling studies (Najjar et al. 2009; Milly et al. 2005; Hayhoe et al. 2007).

Table 1. WMA Operational Characteristics

\begin{tabular}{|c|c|c|c|c|c|c|}
\hline Reservoir & Manager & $\begin{array}{l}\text { Total storage } \\
\left(10^{6} \mathrm{~m}^{3}\right)\end{array}$ & $\begin{array}{c}\text { Available storage } \\
\left(10^{6} \mathrm{~m}^{3}\right)\end{array}$ & $\begin{array}{c}\text { Watershed area } \\
\left(\mathrm{km}^{2}\right)\end{array}$ & $\begin{array}{l}\text { Upstream distance } \\
(\mathrm{km})\end{array}$ & $\begin{array}{l}\text { Travel time } \\
\quad \text { (days) }\end{array}$ \\
\hline Jennings Randolph & CO-OP, USACE & 109 & 51 & 681 & 320 & 9 \\
\hline Little Seneca & $\mathrm{CO}-\mathrm{OP}$ & 16 & 14 & 54 & 25 & 1 \\
\hline Savage & UPRC & 24 & 23 & 272 & 320 & 9 \\
\hline Patuxent & WSSC & 51 & 39 & 342 & - & - \\
\hline Occoquan & Fairfax & 31 & 30 & 1,533 & - & - \\
\hline
\end{tabular}

Table 2. Global Climate Models Considered

\begin{tabular}{lccc}
\hline Model & Institution & Location & Reference \\
\hline CCSM3 & National Center for Atmospheric Research (NCAR) & United States & Collins et al. (2006) \\
CGM_3.1 & Canadian Centre for Climate Modeling and Analysis & Canada & Flato (2005) \\
CSIRO_MK3 & CSIRO Atmospheric Research & Australia & Gordon et al. (2002) \\
MIROC_3.2 & Center for Climate System Research & Japan & Watanabe et al. (2011) \\
PCM1 & National Center for Atmospheric Research & United States & Washington et al. (2000) \\
\hline
\end{tabular}


Table 3. Projected WMA Population and Demand Change (2010-2040)

\begin{tabular}{|c|c|c|c|c|c|c|}
\hline \multirow[b]{2}{*}{ Water supplier } & \multicolumn{2}{|c|}{ Population in millions } & \multicolumn{4}{|c|}{ Water demand $\left(10^{3} \mathrm{~m}^{3} /\right.$ day $)$} \\
\hline & 2010 & 2040 & 2010 & 2020 & 2030 & 2040 \\
\hline Fairfax & 1.54 & $2.03(32.0 \%)$ & 663 & $755(13.8 \%)$ & $826(24.5 \%)$ & $866(30.7 \%)$ \\
\hline WSSC & 1.72 & $2.01(16.6 \%)$ & 651 & $707(8.6 \%)$ & $746(14.7 \%)$ & $771(18.6 \%)$ \\
\hline Aqueduct & 0.98 & $1.23(26.0 \%)$ & 571 & $624(9.2 \%)$ & $652(14.1 \%)$ & $673(17.8 \%)$ \\
\hline Rockville & 0.05 & $0.06(37 \%)$ & 18 & $20(10.4 \%)$ & $22(20.8 \%)$ & $24(31.3 \%)$ \\
\hline Total WMA & 4.28 & $5.33(24.5 \%)$ & 1,903 & $2,106(10.7 \%)$ & $2,246(18.0 \%)$ & $2,335(22.7 \%)$ \\
\hline
\end{tabular}

Note: Percent change from 2010 is presented in parentheses.

Table 4. Projected Sedimentation and Storage Loss (2010-2040)

\begin{tabular}{|c|c|c|c|c|}
\hline \multirow[b]{2}{*}{ Reservoir } & \multicolumn{2}{|c|}{ Usable storage $\left(10^{6} \mathrm{~m}^{3}\right)$} & \multirow{2}{*}{$\frac{\text { Sedimentation rate }}{\left(10^{3} \mathrm{~m}^{3} / \text { year }\right)}$} & \multirow[b]{2}{*}{ Source } \\
\hline & 2010 & 2040 & & \\
\hline Jennings Randolph & 102.5 & $88.1(-14.1 \%)$ & 481 & U.S. Army Corps of Engineers (1963) \\
\hline Little Seneca & 13.8 & $12.1(-12.3 \%)$ & 57 & Hagen et al. (1998) \\
\hline Occoquan & 29.5 & $25.0(-15.4 \%)$ & 151 & CDM (2002) \\
\hline Patuxent & 38.1 & $35.4(-7.2 \%)$ & 91 & Ortt et al. (2007) \\
\hline Savage & 23.3 & $21.2(-8.8 \%)$ & 68 & Ahmed et al. (2010) \\
\hline
\end{tabular}

Note: Percent change from 2010 is presented in parentheses.

Daily streamflow was generated for USGS Stream Gauge 01646500, located on the Potomac River near the Little Falls pumping station in Washington, DC and spatially disaggregated to daily streamflow and precipitation values at the necessary upstream sites using the Method of Fragments (Srikanthan and McMahon 1982; Porter and Pink 1991), in keeping with the approach of Stagge and Moglen (2014). Flows were bias-corrected using quantilequantile mapping to remove residual model bias, particularly at the upstream sites.

\section{Demand and Sedimentation Projections}

Demand projections (Table 3) were based on the most recent population and demand projections for the WMA (Ahmed et al. 2010). This projection evaluates demand change through the year 2040 , modeling beyond the 20-year forecast legally mandated to be performed once every 5 years. These predictions are based on recent water-use information provided by the WMA water suppliers and demographic projections from the most recent Metropolitan Washington Council of Governments (MWCOG) Round 7.2 Cooperative Forecast (MWCOG 2009). Demand change beyond year 2040 is not considered in this study because water demand forecasts tend to become unreliable beyond the 30-year horizon in this region (Ahmed et al. 2010), given the added uncertainty of population change and innovations in water efficiency.

Sedimentation rates (Table 4) were based on historical trend analysis (Ahmed et al. 2010) using the Kendall-Theil Robust Line (Sen 1968). This nonparametric method is a popular alternative to linear regression and is more robust to outliers. The rate of sedimentation was assumed to remain constant for all future time steps, but was only projected until 2040 to match demand changes. This limit on the time horizon was meant to account for uncertainty in sediment capture methods or land-cover change.

\section{Optimization of Operating Rules}

Optimization of system operating rules was carried out in a manner similar to that used by Stagge and Moglen (2014), using S-metric selection-evolutionary multiobjective optimisation algorithm (SMSEMOA) (Emmerich et al. 2005; Beume et al. 2007), a steady-state multiobjective evolutionary algorithm designed to maximize the multidimensional hypervolume (S-metric) dominated by a finite number of points. Hypervolume metrics, developed by Zitzler and Thiele (1998) and Fleischer (2003), are invariant to objective scaling, tend to converge on the Pareto set, and assign a greater weight to regions with unique points or high curvature in the objective space. Optimization was carried out using the EMOA $R$ package (Mersmann 2011) with simulated binary crossover (SBX) and polynomial mutation. This optimization scheme has proven efficient and effective relative to other multiobjective evolutionary algorithms in benchmark studies (Beume et al. 2007).

Within the range of available water resources optimization techniques, evolutionary, or genetic, algorithm solvers have proven successful because of their robustness and flexibility (Chen 2003; Momtahen and Dariane 2007; Oliveira and Loucks 1997; Wardlaw and Sharif 1999). Evolutionary algorithms are capable of searching large and complex decision spaces and evaluating nonlinear and nonconvex objective functions. Multiobjective evolutionary algorithm optimization solves for a set of compromise solutions, termed the Pareto optimal front, which represent optimal solutions that cannot be improved without affecting the other objectives.

Six objective functions were developed in conjunction with water suppliers and the ICPRB and designed to cover the range of potential benefits within the Potomac River system. Target volumes and flows were often based on legal agreements, such as the Low Flow Allocation Agreement (U.S. Army Corps of Engineers 1982). Because the functional limit of current multiobjective evolutionary algorithms has been shown to be approximately 10 objectives (Reed et al. 2013), this optimization model uses six objectives. Each objective is followed by the units of that objective in parentheses:

1. Shortage, which minimizes delivery shortages to the water suppliers (volume);

2. Storage, which minimizes low storage volumes in any of the reservoirs (volume);

3. Flowby, which minimizes days when flow in the Potomac does not exceed low-flow requirements (days of violation);

4. Rec Season, which minimizes days during the recreation season that Jennings Randolph levels fall below recreation facilities (days of violation); 
5. Whitewater, which minimizes days when whitewater releases cannot be made because of low storage volume (days of violation); and

6. Env Flows, which minimizes days when flow in the Potomac falls below recommended environmental levels for three consecutive days (days of violation).

These objectives are presented as a constrained multiobjective optimization problem, identical to that posed by Stagge and Moglen (2014)

Minimize $Z=Z_{\text {Short }}, Z_{\text {Stor }}, Z_{\text {Flowby }}, Z_{\text {RecSeason }}, Z_{\mathrm{WW}}, Z_{\text {EnvFlows }}$

$Z_{\text {Short }}=\sum_{i} \sum_{t=0}^{n} \begin{cases}\frac{\operatorname{Dem}_{i}(t)-\operatorname{Del}_{i}(t)}{\operatorname{Dem}_{i}(t)} & \text { if } \operatorname{Dem}_{i}(t)>\operatorname{Del}_{i}(t) \\ 0 & \text { otherwise }\end{cases}$

$Z_{\text {Stor }}=\sum_{j} \sum_{t=0}^{n} \begin{cases}100-6 \times \operatorname{Stor}_{j}(t) & \text { if } 0 \leq \operatorname{Stor}_{j}(t)<10 \% \\ 60-2 \times \operatorname{Stor}_{j}(t) & \text { if } 10 \leq \operatorname{Stor}_{j}(t)<20 \% \\ 40-\operatorname{Stor}_{j}(t) & \text { if } 20 \leq \operatorname{Stor}_{j}(t)<40 \% \\ 0 & \text { if } \operatorname{Stor}_{j}(t) \geq 40 \%\end{cases}$

$$
Z_{\text {Flowby }}=\sum_{k} \sum_{t=0}^{n}\left(\frac{Q_{k}(t)<Q_{\text {Flowby }}}{n}\right)
$$

$$
\begin{gathered}
Z_{\text {Rec Season }} \\
=\sum_{t=0}^{n_{\text {Rec Season }}}\left[\left(\frac{\operatorname{Elev}_{\mathrm{JR}}(t)>\operatorname{Elev}_{\text {Beach }}}{n_{\text {Rec Season }}}\right)+2 \times\left(\frac{\operatorname{Elev}_{\mathrm{JR}}(t)>\operatorname{Elev}_{\mathrm{WV}}}{n_{\text {Rec Season }}}\right)\right. \\
\left.+5 \times\left(\frac{\operatorname{Elev}_{\mathrm{JR}}(t)>\operatorname{Elev}_{\mathrm{MD}}}{n_{\text {Rec Season }}}\right)\right] \\
Z_{\mathrm{WW}}=\sum_{t=0}^{n_{\mathrm{WW}}}\left(\frac{Q_{\mathrm{WW}}(t)=0}{n_{\mathrm{WW}}}\right)
\end{gathered}
$$

$$
\begin{aligned}
& Z_{\text {EnvFlows }} \\
& =\sum_{t=0}^{n}\left\{\frac{\left[Q_{\mathrm{LF}}(t) \text { and } Q_{\mathrm{LF}}(t-1) \text { and } Q_{\mathrm{LF}}(t-2)\right]<757 \times 10^{3} \mathrm{~m}^{3} / \text { day }}{n}\right\}
\end{aligned}
$$

where each of the $Z$ terms = individual objective functions; for all objective functions, $n=$ total number of days in the time series; $i=$ five individual water suppliers; and $j=$ six reservoir storage accounts: (1) Jennings Randolph Water Quality, (2) Jennings Randolph Water Supply, (3) Savage, (4) Patuxent, (5) Occoquan, and (6) Little Seneca. $Z_{\text {Short }}$ [Eq. (1b)] = percent water delivery shortage at all supply points, including WSSC, Fairfax Water, USACE, city of Westernport, Maryland, and city of Rockville, Maryland; Dem $_{\mathrm{i}}=$ daily demand; Del $_{\mathrm{i}}=$ daily delivery; and $Z_{\text {Stor }}=$ penalty imposed when reservoir usable storage falls below $40 \%$ of the usable storage in the baseline year 2012. Penalties increase as storage approaches zero using a piecewise function that approximates the existing drought restriction setpoints (MWCOG 2000). $Z_{\text {Flowby }}=$ all days when the legally prescribed flowby, $Q_{\text {Flowby }}$, is not satisfied by flow, $Q_{k}$, at each of the $k$ locations. The pertinent flowbys are $227 \times 10^{3} \mathrm{~m}^{3} /$ day at Luke, $1140 \times 10^{3} \mathrm{~m}^{3} /$ day at
Great Falls, and $379 \times 10^{3} \mathrm{~m}^{3} /$ day at Little Falls. $Z_{\text {Rec Season }}$ [Eq. $(1 e)]=$ summer recreation season, which occurs each year between May 1 and Aug 31, represented in the function by $T_{\text {Rec Season }}$. During this period, water managers strive to maintain water levels in the Jennings Randolph Reservoir, represented as Elev $_{\mathrm{JR}}$, above three recreation access points. These points, termed $E_{\mathrm{Beach}}, E_{\mathrm{WV}}$, and $E_{\mathrm{MD}}$, are 443,440 , and $433 \mathrm{~m}$, respectively. $Z_{\mathrm{Ww}}$ [Eq. $\left.(1 f)\right]=$ ratio of days when whitewater releases, $Q_{\mathrm{Ww}}$, cannot be made because of low storage volume. Whitewater releases are set to occur on the 15 th and 30th of April and May, whose set is represented as $T_{\mathrm{WW}}$. $Z_{\text {Env Flows }}[$ Eq. $(1 g)]$ uses a measure to summarize water supply activity's effect on the ecological health of the Potomac River. Although the legal flowby requirement below Little Falls is set at $757 \times 10^{3} \mathrm{~m}^{3}$ /day, the Potomac Basin Large River Environmental Flow Needs study stated that there "is strong concern that a continuous, multi-day period of flows at or very close to $379 \times$ $10^{3} \mathrm{~m}^{3}$ /day would be injurious to the biota" (Cummins et al. 2010). This function sums the number of occurrences when flow below Little Falls, $Q_{\mathrm{LF}}$, remains below $757 \times 10^{3} \mathrm{~m}^{3} /$ day for three or more consecutive days.

Five operating-rule modifications were considered based on recommendations by water suppliers and stakeholders. These rule modifications span a range of typical water management and conservation approaches and are identical to those considered by Stagge and Moglen (2014): (1) the buffer equation that shifts load between the upstream (Jennings Randolph) and downstream (Little Seneca) mainstem Potomac reservoirs; (2) load shifting, which shifts load from the Potomac to the off-line reservoirs; (3) metropolitan demand restrictions; and seasonal reservoir-release rule curves for the (4) Jennings Randolph and (5) Patuxent Reservoirs. Each candidate rule was optimized separately to determine its potential adaptation effect. Adaptation rules were generated using both the historical record and the Commonwealth Scientific and Industrial Research Organisation (CSIRO) (Gordon et al. 2002) A2 scenario (2070-2099), both subject to year 2040 levels of demand and sedimentation. The CSIRO output was chosen as representative of SRES A2 conditions at the end of the next century, and the A2 Scenario was chosen as the most extreme case. In verification tests, the CSIRO model consistently produced good statistical agreement with the historical record across daily, monthly, and annual time steps.

\section{Results}

\section{Projected Changes to WMA Reliability}

Three major processes are projected to affect the reliability of the WMA water supply system over the next century. These are demand change, reservoir sedimentation, and climate change. To identify the relative impact of these processes on the system, the system was simulated while adjusting to each parameter in isolation.

\section{Vulnerability Caused by Demand Change}

Demand forecasts predict a population increase of approximately 1 million (25\%) between 2010 and 2040, which corresponds to a projected water demand increase of $430 \mathrm{~m}^{3} / \mathrm{d}$ (23\%; Table 3) (MWCOG 2009). The greatest increase in population, and therefore water demand, is projected to occur within Fairfax Water's service area of northern Virginia. Demand increase for Fairfax Water is projected to increase by $31 \%$ between 2010 and 2040, whereas the WSSC and Washington Aqueduct service areas are expected to see increased demand of 19 and 18\%, respectively. The City of Rockville, Maryland, which maintains a separate water supply, is projected to have a relatively large increase in demand by 

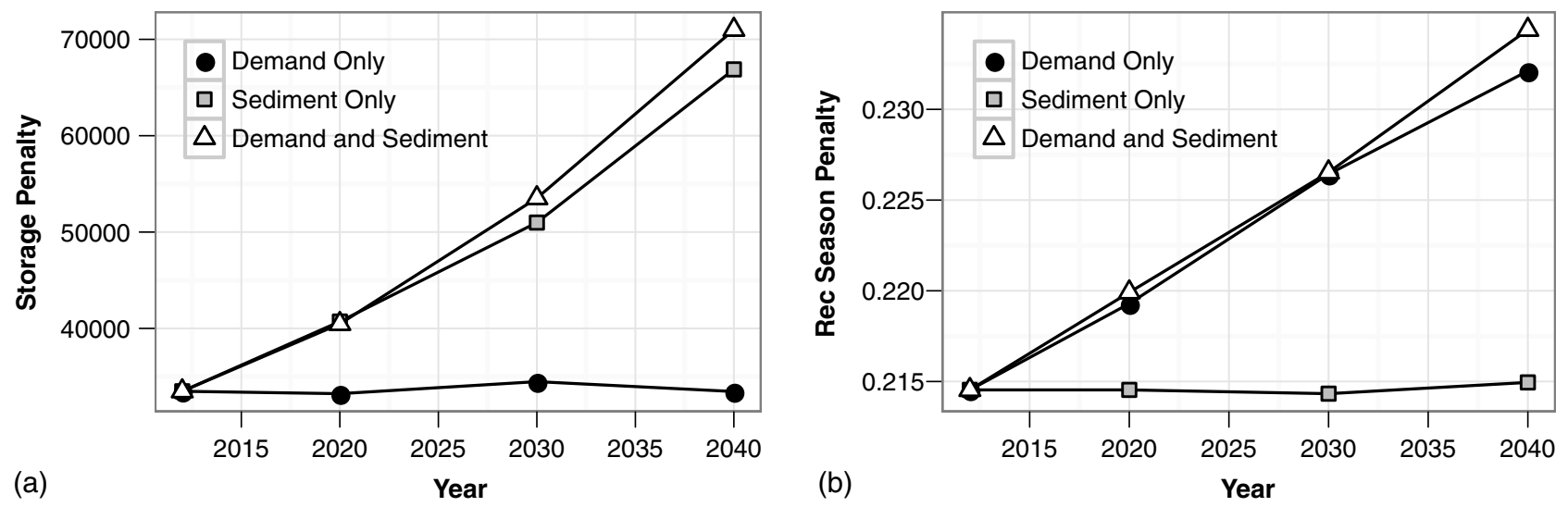

Fig. 2. Effect of demand increase and reservoir sedimentation on (a) storage and (b) recreation season objectives

percent $(31 \%)$, but this remains a small portion of the total WMA water supply because of Rockville's small service area.

This projected increase in demand will produce a consistent increase in storage penalty failures, $Z_{\text {Stor }}$, and recreation season failures, $Z_{\text {RecSeason }}$ (Fig. 2). However, impacts are different, with sedimentation strongly affecting available storage [Fig. 2(a)], and increased demand strongly affecting recreation season storage [Fig. 2(b)]. By 2040, this increase in demand alone will result in an additional loss of approximately 0.5 days/year with access to the beach (2.0\% increase) and 0.9 days/year with access to the West Virginia boat ramp (58.3\% increase). Although this loss of recreation time may not appear large, a $58.3 \%$ increase in the more severe West Virginia boat-ramp failures suggests that demand will drive a loss of recreation revenue. Additionally, recreation failures tend to occur in extended groups, rather than a single instance. In this way, the additional failures may have a considerable effect on individual recreation seasons. Although increased demand does not dramatically affect WMA storage across all reservoirs [Fig. 2(a)], by year 2030, it begins to adversely affect storage in the Little Seneca Reservoir, shown as an increased deviation between sedimentation-only scenarios and combined sedimentation and demand.

\section{Vulnerability Caused by Sedimentation}

Usable reservoir storage volume is expected to decrease because of the deposition of sediment carried by reservoir inflows over time. Reservoirs in the WMA water supply system are projected to lose $7-15 \%$ of their usable storage volume because of sedimentation in the 30 years between 2010 and 2040. Based on the most recent survey, the sedimentation rate in the Jennings Randolph Reservoir is particularly high relative to the other reservoirs (Table 4), and much greater than the original design sedimentation rate of $25 \mathrm{~m}^{3}$ /year (Burns and MacArthur 1996). By year 2040, the storage-capacity loss in the Jennings Randolph Reservoir is projected to be $25 \%$ of the original storage volume (14.1\% between 2010 and 2040). Despite these predictions of storage loss, sedimentation rates tend to change with time, as the sediment contribution of upstream watersheds change. Increased development tends to increase sediment load per area (Allmendinger et al. 2007), although this effect may be mitigated by improvements in nonpoint-source runoff treatment. The Jennings Randolph watershed, historically home to coal mining, has seen a decrease in this industry and has been subject to increased oversight with respect to nonpoint-source runoff.

Reservoir sedimentation is expected to increase the frequency and severity of reservoir storage failures, defined as usable storage less than $40 \%$ by $Z_{\text {Stor }}$ (Fig. 2). This increase is attributable primarily to storage failures in the Patuxent and Savage Reservoirs. Interestingly, the Jennings Randolph and Little Seneca water supply reservoirs do not develop storage failures until the year 2040 sedimentation level. This suggests that there may be opportunities for improving $Z_{\text {Stor }}$ when storage becomes lost to sedimentation through changes in how load is allocated among the reservoirs. Because $Z_{\text {RecSeason }}$ is strongly tied to storage in the Jennings Randolph, it is not surprising that $Z_{\text {Rec Season }}$ is relatively unaffected by sedimentation losses (Fig. 2). Furthermore, sedimentation has little impact on flow measures $Z_{\text {Flowby }}$ and $Z_{\text {EnvFlows }}$.

\section{Vulnerability Caused by Climate Change}

Output from five GCM simulations (Table 2) was used to generate streamflow and precipitation throughout the Potomac watershed at 30-year intervals (2010-2039, 2040-2069, and 2070-2099). These simulations predict a slight increase $(1-7 \%)$ in mean annual flow over the next century, with increases during the winter and early spring, followed by decreased flow during summer (Stagge and Moglen 2013; Najjar et al. 2009; Hayhoe et al. 2007). Projections also show that summer flows will be characterized by longer periods of low flow (Tebaldi et al. 2006), with shorter but more intense storm events and an earlier occurrence of the annual minimum flow. As expected, the highest emission scenario, SRES A2, produced the most severe shifts in streamflow, whereas the low-emission scenario, SRES B1, produced a more modest change.

The effect of climate change alone on water supply reliability in the WMA region is shown graphically in Fig. 3. Climate change simulations project an increase (worsening) for nearly all objective functions over the next century. Results presented in Fig. 3 account for model bias by using quantile-quantile bias correction and always comparing projections against current conditions simulated using the same GCM. Interestingly, the greatest change for most objective functions occurs during the first part of the upcoming century (2010-2039), despite streamflow trends continuing consistently until 2099 (Stagge and Moglen 2013).

When examined in greater detail, the climate change scenarios result in an increase in the frequency of Patuxent and Savage storage failures, although the severity of these failures actually tends to decrease throughout the century. This is partially because load is shifted to other reservoirs such as the Little Seneca and the Occoquan, which previously did not produce storage failures, but begin to once subjected to climate change streamflows. Although storage in the Jennings Randolph Reservoir is never low enough to be considered a storage failure, climate change conditions greatly decrease the number of days with access to the Jennings Randolph 

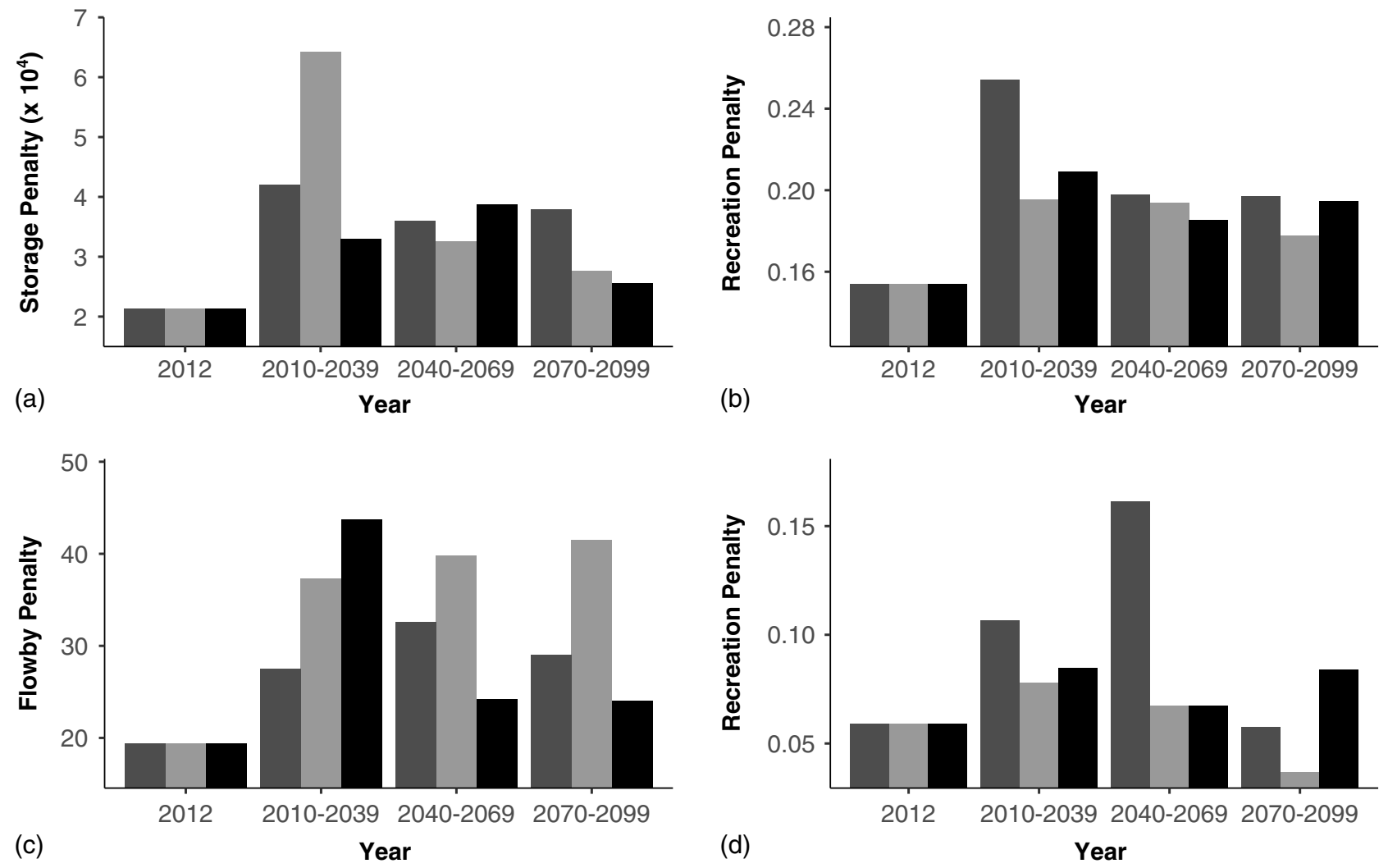

Scenario

A2

A1b

B1

Fig. 3. Effect of climate change on system objectives: (a) storage; (b) recreation season; (c) flowby; (d) whitewater (lines represent the mean of all five considered GCMs for the SRES A2, A1b, and B1 emission scenarios)

beach by 3.9-5.2 days/year. Access to the West Virginia boat dock will be decreased by an average of 0.4-1.3 days/year. Whitewater releases are predicted to be curtailed an additional 4-14 days over the simulation period, a decrease of $18-41 \%$.

\section{Adaptation Strategies}

As expected based on the vulnerability portion of this study, runs combining the climate projections of the 2070-2099 A2 emissions scenario with 2040 demand change and sedimentation was the most challenging scenario for the WMA system. The value of implementing adaptation strategies to this extreme case was determined by comparing system penalties (objective function values) using optimized rules to current rules (Table 5). These results show that adjustments to the buffer equation can produce the greatest improvement

Table 5. Optimization Results for Future Conditions (CSIRO A2, 2070-2099 Climate)

\begin{tabular}{lrrcrr}
\hline Adaptation strategy & $Z_{\text {Stor }}$ & $Z_{\text {Flowby }}$ & $Z_{\text {RecSeason }}$ & $Z_{\text {WW }}$ & $Z_{\text {EnvFlows }}$ \\
\hline Buffer equation & 20.71 & 50 & 37.79 & 88 & 15.20 \\
Load shifting & 1.29 & 8.33 & 0 & 0 & 4.09 \\
JR rule curve & 1.27 & 16.67 & 9.24 & 98 & 15.20 \\
Patux rule curve & 6.39 & 4.17 & 0 & 0 & 2.34 \\
Demand restriction & 1.46 & 4.17 & 0.52 & 0 & 5.26 \\
\hline
\end{tabular}

Note: All values represent the maximum percentage improvement relative to simulations using existing operating rules. under future conditions for most objectives. Load shifting to reservoirs off the mainstem offers modest improvements, primarily to the flowby penalty, whereas modifying demand restricts produces the smallest impact. Modification of the Jennings Randolph (JR) rule curve is effective for addressing objectives related to recreation storage and Potomac low flows, and Patuxent rule-curve modifications decrease reservoir storage penalties. No system shortage failures were noted and were, therefore, not included in the discussion. This is because the existing operating rules prioritize satisfying daily demand at the expense of violating the other objectives.

\section{Buffer Equation}

Within the WMA water supply operating rules, the buffer equation is designed to balance storage levels between the reservoirs on the main stem of the Potomac River, the upstream Jennings Randolph Reservoir, and downstream Little Seneca Reservoir. Reservoir releases are calculated based on estimated demand; however, the buffer equation adds a so-called buffer flow to Jennings Randolph releases to account for imbalance in percent usable storage between the Jennings Randolph water supply volume and downstream Little Seneca storage. The existing buffer equation is represented by a solid diagonal line in Fig. 4, in which a negative storage imbalance recommends a larger than necessary release from the Jennings Randolph to reduce load on the Little Seneca. The right side of these plots (positive imbalance) reduces Jennings Randolph releases under the assumption that the deficit will be satisfied through releases from the downstream Little Seneca Reservoir. Under the current policy, the slope of the buffer equation [Figs. 4(a and b)] 

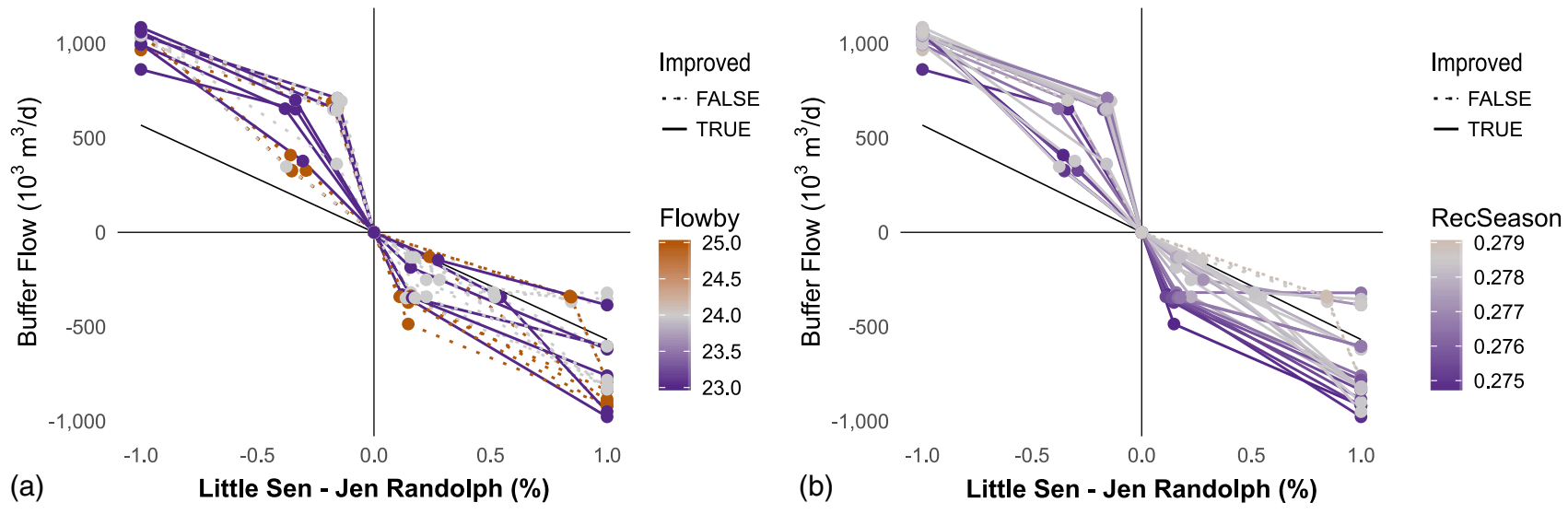

Fig. 4. Optimized buffer equation under 2070-2099 climate change conditions with respect to (a) flowby and (b) recreation season; current operating rules are shown by the diagonal solid line; each nondominated solution is presented with the line type showing improvement (solid) or worsening (dotted) of the objective function relative to current policy and shading corresponding to the severity of this change

is linear for both of these situations, with a maximum buffer flow of $568 \mathrm{~m}^{3} / \mathrm{d}$.

Modification of the buffer equation produced the largest improvement of the considered modifications for future conditions, reducing the frequency of missed flowby targets $\left(Z_{\text {Flowby }}\right)$ and number of consecutive days with extreme low flows $\left(Z_{\text {EnvFlows }}\right)$ (Table 5). Buffer-equation adjustments were partially capable of mitigating the impact of climate change, reducing most penalties for the 2070-2099 scenario to levels simulated with only demand and sedimentation. However, no version of the buffer equation was capable of reducing systemwide penalties under climate change, demand increase, and sedimentation to current levels.

The buffer equation reduces $Z_{\text {Flowby }}$ and $Z_{\text {EnvFlow }}$ failures by increasing the buffer flow when usable Little Seneca storage (\%) is lower than that of Jennings Randolph [Fig. 4(a)]. Under these optimized rules, a much greater release is made from the Jennings Randolph Reservoir in this situation, which in turn reduces load on the Little Seneca Reservoir and acts as a pulse in the Potomac River to prevent extreme low flows downstream of Little Falls. Similar recommendations were made for current climate conditions (Stagge and Moglen 2014), and the shape of the optimal buffer equation does not change substantially with time between current conditions and the 2070-2099 projection.

Although the right side of the equation has little effect on $Z_{\text {Flowby }}$, it is important for improving $Z_{\text {RecSeason }}$ [Fig. 4(b)], particularly for the 2070-2099 projection. This extreme scenario produced the most stress on the Jennings Randolph storage, where recreation storage is measured. Therefore, it follows that a lower buffer equation on the right side would reduce Jennings Randolph releases when storage is low relative to other reservoirs, thereby protecting recreation storage.

\section{Load Shifting}

Whereas the buffer equation deals with balancing releases along the Potomac River, load shifting controls how demand is allocated to the offline reservoirs, the Patuxent and Occoquan. When predicted flow in the Potomac River is not sufficient to satisfy predicted demand, production at the Patuxent and Occoquant water-treatment plants is temporarily increased above typical production levels. Following this load-shifting event, production at the offline reservoirs is curtailed an equivalent amount in order to replenish storage. Load shifting occurs only when storage in the Jennings Randolph, Little Seneca, Occoquan, and Patuxent remains above trigger points, called load-shift storage indices.
Modification of the storage indices and load-shift equation has relatively little impact on the WMA system in simulations of future demand/sedimentation conditions and climate change (Table 5). Although changes to load shifting generally results in better performance than the current policy, this improvement cannot completely mitigate the effects of either climate change or demand and sedimentation change. No trends exist over time among the optimized load-shifting parameters, suggesting that the effectiveness of load shifting has been maximized and that no further improvements will be realized with time.

Adjustments to the load-shift equation were shown to be effective under current conditions because the Occoquan Reservoir had unused storage, which could be used to reduce load on the already stressed Patuxent Reservoir (Stagge and Moglen 2014). However, as future conditions further constrain and stress the WMA system, the additional Occoquan storage is not as readily available, as shown by increases in Occoquan storage penalties (storage $<40 \%$ ). Increasing the load-shift storage indices was another method of decreasing load on the stressed Patuxent Reservoir under current climate conditions (Stagge and Moglen 2014). However, under future conditions, this puts undue strain on the Little Seneca Reservoir, suggesting that the benefits of this approach are already maximized.

\section{Monthly Rule Curves}

All reservoirs in the WMA water supply system operate, at least during a portion of the year, according to zone-based rule curves, except for Little Seneca, which maintains a full storage volume throughout the year. To determine adaptation potential, operating rule curves for the Jennings Randolph and Patuxent Reservoirs were evaluated using multiobjective optimization. The Jennings Randolph Reservoir was chosen for evaluation because it is the primary water supply reservoir on the Potomac River, whereas the Patuxent Reservoir was most vulnerable to storage failures. Jennings Randolph water quality storage is managed by the Baltimore District of the U.S. Army Corps of Engineers and uses three zonebased rule curves (high, medium, and low) to guide water quality releases during the non-recreation-season months (SeptemberApril). These releases are designed to approximate the natural contribution of the Potomac River's impounded North Branch while refilling the reservoir prior to the summer recreation season.

Modifications of the Jennings Randolph rule curves primarily improved objectives related to Jennings Randolph storage (Table 5), reducing $Z_{\text {RecSeason }}$ by $0.1-9.2 \%$ and $Z_{\mathrm{WW}}$ by $83.3-98 \%$. It had 
little effect on storage failures because these primarily occurred in other reservoirs or during the summer season when the seasonal rule curves are not in effect. The projected climate change shift toward higher flows during the winter and spring, followed by lower flows in the summer and early fall, was mirrored by the optimized Jennings Randolph Reservoir rule curves. The optimized curves increased trigger points between March and May, immediately prior to the recreation season, forcing the Jennings Randolph Reservoir to operate more conservatively, making smaller releases during this time. In this way, the increase in spring flows is used to increase the storage buffer prior to a summer flow regime characterized by more severe low flows.

Modification of the Patuxent rule curve is designed to maintain adequate storage in the highly stressed Patuxent Reservoir while also providing additional water supply for the WSSC. Simulations suggest that the Patuxent Reservoir is vulnerable during future droughts, typically entering low storage $(<40 \%)$ conditions before the remaining WMA reservoirs and thereby contributing to the $Z_{\text {Stor }}$ penalty. For future conditions, adjusting the Patuxent rule curves improves $Z_{\text {Stor }}$ by 6.1-6.4\% (Table 5). The Patuxent Reservoir operates using two rule curves that control daily water-treatment withdrawals based on storage zone. The adaptation improvement is attributed to an increase of approximately 1,000-1,500 $\times 10^{3} \mathrm{~m}^{3}$ in both the upper and lower rule curves between the months of September and February. This modification allows the Patuxent Reservoir to refill more effectively if storage is low during the fall and winter by decreasing water-treatment rates and shifting load back to the Potomac River. Although this shift is similar in both the climate change simulation and the sediment and demand-change simulation, the optimal rule curves deviate in midsummer. Likely because of increased summer drought severity attributable to climate change, the optimized upper and lower Patuxent rule curves for this scenario tend to be approximately $300 \times 3 \mathrm{~m}^{3}$ higher through the months of July and August. This allows the Patuxent Reservoir to operate even more conservatively for the most extreme scenario.

\section{Demand Restrictions}

The Metropolitan Washington Council of Governments standardized the implementation of water-use restrictions by setting three demand-restriction levels: voluntary, mandatory, and emergency, each with a unique storage trigger (MWCOG 2000). As part of the MWCOG agreement, all regional governments agreed to abide by these triggers, declaring restrictions simultaneously. Voluntary restrictions are triggered when combined storage in the Jennings Randolph and Little Seneca Reservoirs falls below 60\%. Trigger points for mandatory and emergency restrictions are set at 25 and $5 \%$ for Jennings Randolph or Little Seneca storage, respectively (Table 6). This is a simplification of the actual MWCOG demandrestriction rules, but matches actual operations very well.

In a review of the WMA under current conditions, Stagge and Moglen (2014) found that the existing MWCOG demandrestriction triggers would never be implemented during a repeat of the historical streamflow record with current demand levels. Because stress on the WMA water supply increases with time, the likelihood of demand restrictions increases, highlighting the importance of an effective demand-restriction policy. Under the existing MWCOG policy and 2040 demand and sedimentation levels but no climate change, the WMA service area would experience voluntary restrictions once every 26 years, on average. Simulations based on the CSIRO 2070-2099 A2 climate scenario with demand change and sedimentation increase this frequency to once every 20 years, with $75 \%$ of voluntary restriction years ultimately requiring mandatory demand restrictions.

Improvements because of demand restrictions are limited and primarily focus on $Z_{\text {Flowby }}$ and $Z_{\text {EnvFlows }}$. With regard to storage, these changes particularly improve storage in the Patuxent and Occoquan Reservoirs. System performance is improved by increasing the voluntary trigger from $60 \%$ of Jennings Randolph and Little Seneca storage to $74-85 \%$ (Table 6). Operations also improved when the mandatory restriction trigger point was decreased from 25 to $17-25 \%$ for Jennings Randolph storage but increased from 25 to 24-59\% for Little Seneca storage (Table 6). The trigger point is higher for the Little Seneca because it is more vulnerable because of its small size and slow refill rate. Trigger points for emergency restrictions were also increased, although these were so infrequently used that there is significant uncertainty in the results. The benefits of these adaptation strategies are tempered by an increase in the frequency of demand restrictions, for example, doubling the frequency of voluntary restrictions from once every 20 years to once every 10 years.

Modifying the percent demand restrictions during the summer season (June-September) did not produce significant improvement in the objective functions. However, some improvements for $Z_{\text {Flowby }}$ and $Z_{\text {EnvFlows }}$ were realized by increasing the percent demand restrictions outside of the summer period to resemble summer restrictions. Continuing the more severe restrictions outside the summer drought period allowed reservoirs to refill prior to the next summer, better handling multiyear droughts.

\section{Discussion}

This study uses evolutionary algorithms to optimize water management strategies. However, other alternatives exist and could be substituted into this framework to identify adaptation strategies. More traditional optimization techniques such as linear or nonlinear programming have the benefit of quick convergence to the global optima, but would require several simplifying assumptions with regard to constraints, objectives, and adaptation strategies (Labadie 2004). More recent heuristic optimization techniques could also be considered, such as particle-swarm optimization (Reddy and Nagesh Kumar 2007; Taormina and Chau 2015), fuzzy programming (Chen and Chang 2010), or simulated annealing (Li and Wei 2008). Similar to the evolutionary algorithm approach used here, these alternative optimization approaches add a great deal

Table 6. Optimized Demand-Restriction Triggers in Percentage of Usable Storage

\begin{tabular}{lcccrrr}
\hline & \multicolumn{3}{c}{ Jennings Randolph } & \multicolumn{2}{c}{ Little Seneca } \\
\cline { 2 - 6 } Demand trigger & MWCOG & 2040 & 2070 A2 & & MWCOG & 2040 \\
\hline Voluntary & 60 & $74-85$ & $74-83$ & 60 & $73-82$ \\
Mandatory & 25 & $17-25$ & $18-25$ & 25 & $72-83$ \\
Emergency & 5 & $11-17$ & $11-15$ & 5 & $26-59$ \\
\hline
\end{tabular}

Note: Current demand-restriction triggers are presented as a single value, termed MWCOG, whereas optimized results for the 2040 Demand and Sedimentation case, termed 2040, and the CSIRO A2 2070-2099 case, denoted as 2070, are presented as a range across all nondominated solutions. 
of flexibility, sacrificing the guarantee of finding global optima and requiring more processing time. More detailed comparisons of modern optimization techniques are available in several methodology overviews (Ahmad et al. 2014; Sahinidis 2004; Labadie 2004).

From among these alternatives, evolutionary algorithms were chosen because they are one of the most common heuristic optimization techniques and are proven to be robust, flexible, and capable of searching large and complex decision spaces (Reed et al. 2013). Flexible optimization schemes are important in complex systems like the WMA because they can be directly linked to hydrologic models and can handle uncertainty caused by time lags in water delivery and complex objective functions.

The objectives in this study were selected in close collaboration with the water suppliers and were designed to closely match the goals of the system as codified in legal agreements. However, there would be a benefit to considering new and more complex objective functions to determine how the set of optimal solutions would change. For example, the environmental and low-flow objectives are based on quite simple legal requirements, but the objectives could be better targeted to ecological health by collaborating with ecologists and fisheries experts. Similarly, there may be some benefit to considering more complex economic drivers and objectives, using a framework similar to that of Harou et al. (2009).

This study used CMIP3 projections downscaled to daily streamflow using the method of Stagge and Moglen (2013) rather than more traditional approaches, such as statistical or dynamical downscaling. The benefit of the Stagge and Moglen (2013) approach is that it generates a suite of ensemble members to better test vulnerability over a wider range of feasible flows and does not require a full hydrologic model. As described by Stagge and Moglen (2013), the existing Potomac River model performed poorly for low flows, whereas the alternative approach better captured these. The CMIP3 set of GCM runs has been updated with CMIP5 output (Wuebbles et al. 2014). It would be helpful to consider CMIP5 output in the future, although the two experiments agree well with regard to precipitation and drought near the Potomac River (Wuebbles et al. 2014). The largest improvements have been for simulation of monsoon precipitation, which mainly affects more southern and western parts of the United States (Cook and Seager 2013).

\section{Conclusions}

The effects of climate change are increasingly being considered in conjunction with demand change and reservoir sedimentation in forecasts of water supply vulnerability. This study provided an example of how this can be accomplished, using the Washington, DC metropolitan area water supply as a case study. First, system vulnerability arising from projected changes was evaluated using repeated simulation, and then these vulnerabilities were addressed using multiobjective optimization to develop a set of optimized rules under future conditions. These rules form the basis for an adaptation strategy using efficient management without the need for physical improvements.

A systemwide increase in demand of $23 \%$ by the year 2040 is projected to decrease available storage in the Jennings Randolph Reservoir, decreasing the number of recreation days, measured above lake access points. Increased demand is also projected to increase the load on downstream reservoirs, resulting in an increase in consecutive low-flow days. WMA reservoirs are projected to lose $7-15 \%$ of their usable storage volume because of sedimentation between 2010 and 2040, causing an increase in storage failures, particularly in the Patuxent Reservoir. By 2040, the effects of sedimentation alone will begin to cause occasional storage failures in the Jennings Randolph and Little Seneca Reservoirs as well.

Climate change is also projected to increase water supply vulnerability in the WMA. Climatic trends in the region are toward higher flows in the winter and early spring, followed by more extreme low flows in the summer. Simulations of five GCMs predict an increase in storage failures within the system, with storage failures beginning to occur in the Little Seneca and Occoquan Reservoirs, where historically they did not occur. An increase in storage penalties is accompanied by a decrease in whitewater releases and a doubling of recreation season failures.

Five potential modifications to existing operating rules were evaluated using the multiobjective evolutionary algorithm optimization scheme. None of the optimized operating rules were able to completely mitigate the combined effects of demand change, sedimentation, and climate changes. However, some, such as the buffer equation, were able to mitigate the effect of climate with respect to the objectives. Flowby and environmental flow penalties were decreased by modifying the buffer equation to allow separate equations controlling upstream and downstream imbalances. Results for the load-shift equation remain very similar to the optimized loadshift equation found for current conditions (Stagge and Moglen 2014). This suggests that the effectiveness of this rule is maximized. Optimization of the zone-based rule curves suggests that Jennings Randolph storage should be managed more conservatively during March, April, and May in the future, whereas storage in the Patuxent could be improved by managing the reservoir more conservatively during the refill period (September-February). Evaluation of demand restriction triggers suggests that systemwide operation could be slightly improved by increasing the reservoir storage triggers for minor voluntary restrictions. For the more severe mandatory restriction, the optimized rules suggest a decrease in the Jennings Randolph trigger and an increase in the Little Seneca trigger. In this latter case, the increase in the Little Seneca trigger is attributable to its relatively small size and long refill rate.

Using a combination of synthetic streamflow generation, water resources decision modeling, and multiobjective optimization, the potential vulnerabilities of the WMA water supply system were evaluated. The adaptation strategies outlined here could be implemented in the WMA, although several would require greater coordination and flexibility. This is a common challenge for transboundary and shared watersheds. Furthermore, this study provides a framework for developing and comparing strategies to mitigate the effects of projected demand and climate change with an appropriate adaptation strategy.

\section{Acknowledgments}

This study was conducted while James Stagge was a Via Doctoral Fellow in the Department of Civil and Environmental Engineering at Virginia Tech. He gratefully acknowledges support from the Via program and the Institute for Critical Technology and Applied Science (ICTAS) at Virginia Tech. The authors would also like to thank the Interstate Commission on the Potomac River Basin (ICPRB) and Hydrologics, Inc. for providing data access and research support. The U.S. Department of Agriculture (USDA) prohibits discrimination in all its programs and activities on the basis of race, color, national origin, age, disability, and where applicable, sex, marital status, familial status, parental status, religion, sexual orientation, genetic information, political beliefs, reprisal, or because all or part of an individual's income is derived from any public assistance program. (Not all prohibited bases apply to all programs.) Persons with disabilities who require alternative means 
for communication of program information (Braille, large print, audiotape, etc.) should contact USDA's TARGET Center at (202) 720-2600 (voice and TDD). To file a complaint of discrimination, write to USDA, Director, Office of Civil Rights, 1400 Independence Avenue, S.W., Washington, D.C. 20250-9410, or call (800) 795-3272 (voice) or (202) 720-6382 (TDD). USDA is an equal opportunity provider and employer. The authors would like to thank two anonymous reviewers for their constructive comments regarding this paper.

\section{References}

Ahmad, A., El-Shafie, A., Razali, S. F. M., and Mohamad, Z. S. (2014). "Reservoir optimization in water resources: A review." Water Resour. Manage., 28(11), 3391-3405.

Ahmed, S. N., Bencala, K. R., and Schultz, C. L. (2010). "2010 Washington metropolitan area water supply reliability study. 1: Demand and resource availability forecast for the year 2040." Rep. No. ICPRB 10-01, Interstate Commission on the Potomac River Basin, Rockville, MD.

Aksoy, H. (2003). "Markov chain-based modeling techniques for stochastic generation of daily intermittent streamflows." Adv. Water Resour., 26(6), 663-671.

Allmendinger, N. E., Pizzuto, J. E., Moglen, G. E., and Lewicki, M. (2007). "A sediment budget for an urbanizing watershed, 1951-1996, Montgomery County, Maryland, U.S.A.” J. Am. Water Resour. Assoc., 43(6), 1483-1498.

Beume, N., Naujoks, B., and Emmerich, M. (2007). "SMS-EMOA: Multiobjective selection based on dominated hypervolume." Eur. J. Oper. Res., 181(3), 1653-1669.

Burns, M., and MacArthur, R. (1996). "Sediment deposition in Jennings Randolph Reservoir, Maryland and West Virginia." Proc., 6th Federal Interagency Sedimentation Conf., Interagency Advisory Committee on Water Data, Subcommittee on Sedimentation, Washington, DC.

CDM (Camp, Dresser and McKee). (2002). "Water supply master planning: Identification of future FCWA water supply needs." Fairfax, VA.

Chen, H.-W., and Chang, N.-B. (2010). "Using fuzzy operators to address the complexity in decision making of water resources redistribution in two neighboring river basins." Adv. Water Resour., 33(6), 652-666.

Chen, L. (2003). "Real coded genetic algorithm optimization of long term reservoir operation." J. Am. Water Resour. Assoc., 39(5), 1157-1165.

Collins, W. D., et al. (2006). "The community climate system model version 3 (CCSM3)." J. Clim., 19(11), 2122-2143.

Cook, B. I., and Seager, R. (2013). "The response of the North American monsoon to increased greenhouse gas forcing." J. Geophys. Res.: Atmos., 118(4), 1690-1699.

Cummins, J., et al. (2010). Potomac Basin large river environmental flow needs, Interstate Commission on the Potomac River Basin, Rockville, MD.

Emmerich, M., Beume, N., and Naujoks, B. (2005). "An EMO algorithm using the hypervolume measure as selection criterion." Proc., Evolutionary Multi-Criterion Optimization: Third Int. Conf. (EMO 2005), Vol. 2410, Springer, Berlin, 62-76.

Flato, G. (2005). "The third generation coupled global climate model (CGCM3).” 〈http://www.cccma.ec.gc.ca/models/cgcm3.shtml〉 (Jun. 6, 2017).

Fleischer, M. (2003). "The measure of Pareto optima applications to multiobjective metaheuristics." Evolutionary multi-criterion optimization, C. Fonseca, P. Fleming, E. Zitzler, L. Thiele, and K. Deb, eds., Vol. 2632, Springer, Berlin, 519-533.

Gordon, H. B., et al. (2002). "The CSIRO Mk3 climate system model." Rep. No. 60, CSIRO, Canberra, Australia.

Groisman, P. Y., Knight, R. W., and Karl, T. R. (2001). "Heavy precipitation and high streamflow in the contiguous United States: Trends in the twentieth century." Bull. Am. Meteorol. Soc., 82(2), 219-246.

Groisman, P. Y., Knight, R. W., Karl, T. R., Easterling, D. R., Sun, B., and Lawrimore, J. H. (2004). "Contemporary changes of the hydrological cycle over the contiguous United States: Trends derived from in situ observations.” J. Hydrometeorol., 5(1), 64-85.
Hagen, E. R., Steiner, R. C., and Ducnuigeen, J. L. (1998). Patuxent reservoirs: "Natural" daily inflow development, Interstate Commission on the Potomac River Basin, Rockville, MD.

Harou, J. J., Pulido-Velazquez, M., Rosenberg, D. E., Medellín-Azuara, J., Lund, J. R., and Howitt, R. E. (2009). "Hydro-economic models: Concepts, design, applications, and future prospects." J. Hydrol., 375(3-4), 627-643.

Hayhoe, K., et al. (2007). "Past and future changes in climate and hydrological indicators in the US Northeast." Clim. Dyn., 28(4), 381-407.

Hayhoe, K., et al. (2008). "Regional climate change projections for the northeast USA." Mitigation Adaptation Strategies Global Change, 13(5-6), 425-436.

IPCC (Intergovernmental Panel on Climate Change). (2014). Climate change 2014: Synthesis report. Contribution of working groups I, II and III to the fifth assessment report of the Intergovernmental Panel on Climate Change, Geneva.

Labadie, J. W. (2004). "Optimal operation of multireservoir systems: Stateof-the-art review.” J. Water Resour. Plann. Manage., 10.1061/(ASCE) 0733-9496(2004)130:2(93), 93-111.

Li, X.-G., and Wei, X. (2008). "An improved genetic algorithm-simulated annealing hybrid algorithm for the optimization of multiple reservoirs." Water Resour. Manage., 22(8), 1031-1049.

Mccabe, G. J., Jr., and Ayers, M. A. (1989). "Hydrologic effects of climate change in the Delaware River basin." Water Resour. Bull., 25(6), 1231-1242.

Meehl, G. A., et al. (2007). "The WCRP CMIP3 multimodel dataset: A new era in climate change research." Bull. Am. Meteorol. Soc., 88(9), 1383-1394.

Meehl, G. A., and Tebaldi, C. (2004). "More intense, more frequent, and longer lasting heat waves in the 21st century." Science, 305(5686), 994-997.

Mersmann, M. (2011). EMOA: Evolutionary multiobjective optimization algorithms, Comprehensive R Archive Network (CRAN), Dortmund, Germany.

Milly, P. C. D., Dunne, K. A., and Vecchia, A. V. (2005). "Global pattern of trends in streamflow and water availability in a changing climate." Nature, 438(7066), 347-350.

Momtahen, S., and Dariane, A. B. (2007). "Direct search approaches using genetic algorithms for optimization of water reservoir operating policies." J. Water Resour. Plann. Manage., 10.1061/(ASCE)0733-9496 (2007)133:3(202), 202-209.

Moore, M. V., et al. (1997). "Potential effects of climate change on freshwater ecosystems of the New England/mid-Atlantic region." Hydrol. Process., 11(8), 925-947.

MWCOG (Metropolitan Washington Council of Governments). (2000). "Metropolitan Washington water supply and drought awareness response plan: Potomac River System." Rep. No. 20703, Washington, DC.

MWCOG (Metropolitan Washington Council of Governments). (2009). Round 7.2 cooperative forecasting: Employment, population, and household forecasts to 2030 by traffic analysis zone, Washington, DC.

Najjar, R., Patterson, L., and Graham, S. (2009). "Climate simulations of major estuarine watersheds in the mid-Atlantic region of the US." Clim. Change, 95(1-2), 139-168.

OASIS 3.09.033 [Computer software]. Hydrologics, Columbia, MD.

Oliveira, R., and Loucks, D. P. (1997). "Operating rules for multireservoir systems.” Water Resour. Res., 33(4), 839-852.

Ortt, R. A., VanRyswick, S., and Wells, D. (2007). Bathymetry and sediment accumulation of Tridelphia and Rocky Gorge reservoirs, Maryland Dept. of Natural Resources, Maryland Geological Survey, Coastal and Estuarine Geology, Baltimore.

Palmer, R. N., Smith, J. A., Cohon, J. L., and ReVelle, C. (1982). "Reservoir management in the Potomac River basin." J. Water Resour. Plann. Manage., 108(1), 47-66.

Palmer, R. N., Wright, J. R., Smith, J. A., Cohon, J. L., and ReVelle, C. S. (1979). Policy analysis of reservoir operations in the Potomac River Basin, volume I. Executive summary, Univ. of Maryland, College Park, MD.

Porter, J. W., and Pink, B. J. (1991). "A method of synthetic fragments for disaggregation in stochastic data generation." Hydrology and Water Resources Symp., Institution of Engineers, Perth, Australia, 187-191. 
Pyke, C. R., et al. (2008). "Climate change and the Chesapeake Bay: Stateof-the-science review and recommendations." Publication 08-004, Chesapeake Bay Program Science and Technical Advisory Committee (STAC), Annapolis, MD, 59.

Reddy, M. J., and Nagesh Kumar, D. (2007). "Multi-objective particle swarm optimization for generating optimal trade-offs in reservoir operation." Hydrol. Process., 21(21), 2897-2909.

Reed, P. M., Hadka, D., Herman, J. D., Kasprzyk, J. R., and Kollat, J. B. (2013). "Evolutionary multiobjective optimization in water resources: The past, present, and future." Adv. Water Resour., 51, 438-456.

Sahinidis, N. V. (2004). "Optimization under uncertainty: State-of-the-art and opportunities." Comput. Chem. Eng., 28(6-7), 971-983.

Sen, P. K. (1968). "Estimates of the regression coefficient based on Kendall's Tau.” J. Am. Stat. Assoc., 63(324), 1379-1389.

Sheer, D. P., and Flynn, K. (1983). "Water-supply." Civil Eng., 53(6), 50-53.

Srikanthan, R., and McMahon, T. A. (1982). "Stochastic generation of monthly streamflows." J. Hydraul. Div., 108(3), 419-441.

Stagge, J. H., and Moglen, G. (2014). "Evolutionary algorithm optimization of a multireservoir system with long lag times." J. Hydrol. Eng., 10.1061/(ASCE)HE.1943-5584.0000972, 05014011.

Stagge, J. H., and Moglen, G. E. (2013). "A nonparametric stochastic method for generating daily climate-adjusted streamflows." Water Resour. Res., 49(10), 6179-6193.

Szilagyi, J., Balint, G., and Csik, A. (2006). "Hybrid, Markov chain-based model for daily streamflow generation at multiple catchment sites." $J$. Hydrol. Eng., 10.1061/(ASCE)1084-0699(2006)11:3(245), 245-256.
Taormina, R., and Chau, K.-W. (2015). "Data-driven input variable selection for rainfall-runoff modeling using binary-coded particle swarm optimization and extreme learning machines." J. Hydrol., 529(Part 3), $1617-1632$.

Tebaldi, C., Hayhoe, K., Arblaster, J. M., and Meehl, G. A. (2006). "Going to the extremes." Clim. Change, 79(3-4), 185-211.

U.S. Army Corps of Engineers. (1963). Potomac River Basin report, Dept. of the Army, North Atlantic Division, Baltimore.

U.S. Army Corps of Engineers. (1982). Water supply coordination agreement, Dept. of the Army, Baltimore.

U.S. Census Bureau. (2016). "Metropolitan and micropolitan area population totals datasets: 2010-2015." 〈https://www.census.gov/data/tables /2015/demo/popest/total-metro-and-micro-statistical-areas.html (Mar. $15,2017)$.

Wardlaw, R., and Sharif, M. (1999). "Evaluation of genetic algorithms for optimal reservoir system operation." J. Water Resour. Plann. Manage., 10.1061/(ASCE)0733-9496(1999)125:1(25), 25-33.

Washington, W. M., et al. (2000). "Parallel climate model (PCM) control and transient simulations." Clim. Dyn., 16(10-11), 755-774.

Watanabe, S., et al. (2011). "MIROC-ESM 2010: Model description and basic results of CMIP5-20c3m experiments." Geosci. Model Dev., 4(4), $845-872$.

Wuebbles, D., et al. (2014). "CMIP5 climate model analyses: Climate extremes in the United States." Bull. Am. Meteorol. Soc., 95(4), 571-583.

Zitzler, E., and Thiele, L. (1998). Multiobjective optimization using evolutionary algorithms - A comparative case study, Springer, New York, 292-301. 